\title{
Interactive comment on "Discrete k-nearest neighbor resampling for simulating multisite precipitation occurrence and adaption to climate change" by Taesam Lee and Vijay P. Singh
}

Taesam Lee and Vijay P. Singh

tae3lee@gnu.ac.kr

Received and published: 13 January 2019

The comment was uploaded in the form of a supplement:

https://www.geosci-model-dev-discuss.net/gmd-2018-181/gmd-2018-181-AC2-

supplement.pdf

Interactive comment on Geosci. Model Dev. Discuss., https://doi.org/10.5194/gmd-2018-181, 2018. 